\title{
BMJ Open Characterising common challenges faced by parental caregivers of children with type 1 diabetes mellitus in mainland China: a qualitative study
}

\author{
Huijuan Tong, ${ }^{1}$ Feng Qiu, ${ }^{2}$ Ling Fan (D) ${ }^{3}$
}

To cite: Tong H, Qiu F,

Fan L. Characterising common challenges faced by parental caregivers of children with type 1 diabetes mellitus in mainland China: a qualitative study. BMJ Open 2022;12:e048763. doi:10.1136/ bmjopen-2021-048763

- Prepublication history for this paper is available online. To view these files, please visit the journal online (http://dx.doi. org/10.1136/bmjopen-2021048763).

Received 06 January 2021 Accepted 14 December 2021

Check for updates

(c) Author(s) (or their employer(s)) 2022. Re-use permitted under CC BY-NC. No commercial re-use. See rights and permissions. Published by BMJ.

${ }^{1}$ School of Nursing, Shenyang Medical College, Shenyang,

China

${ }^{2}$ Department of Ophthalmology, Shenyang Fourth People's Hospital, Shenyang, China ${ }^{3}$ Department of Nursing, Shengjing Hospital of China Medical University, Shenyang, China

Correspondence to

Dr Ling Fan;

fanl_sj0512@163.com

\section{ABSTRACT}

Objectives The mental state of parental caregivers affects outcomes in children with type 1 diabetes mellitus (T1DM). This study aimed to qualitatively examine perception of common challenges among parental caregivers of children with T1DM.

Setting Semistructured interviews 45-60 min long were conducted with parental caregivers of children with T1DM. Interview recordings were transcribed and coded in NVivo V.11.0 to observe emergent themes.

Participants Eligible T1DM caregiving parents (parent(s) and/or legal guardian(s)) were identified from caregivers attending visits with children hospitalised or assessed in the Pediatric Neuroendocrinology Department of Shengjing Hospital, China Medical University in Shenyang from January 2018 to June 2019.

Primary and secondary outcome measures Not applicable.

Results A total of 20 T1DM caregiving parents were interviewed, aged 30-53 years, including 7 fathers and 13 mothers, with their children whose mean age was $10.6 \pm 2.45$ years. Content analysis revealed 5 major themes with 13 subthemes, including persistent psychological stress (catastrophic emotions, emotional distress and altered self-efficacy), family function change (altered family life patterns and changes in parental role/ function), challenges in daily management (technical challenges, emotional regulation, parent-child conflict and transition of care autonomy from parent to child), financial burden (cost burden of treatment and altered family economics), and lack of social support (social activity limitations and insufficient support system).

Conclusions The period of emotional disturbance during initial diagnosis, psychological stresses of long-term caregiving, and conflict emerging from transition from parental to child responsibility all can cause psychological response detrimental to parental caregivers and children with T1DM. This work provides compelling evidence for the role of assessment and intervention in parental caregivers' psychological and emotional well-being in diabetes care, as well as for the necessity of improved social and school support for children with T1DM in China.

\section{INTRODUCTION}

Type 1 diabetes mellitus (T1DM) is a common chronic disease in children, and both the
Strengths and limitations of this study

- This is the first qualitative study, which describes the conditions and consequences of young children with type 1 diabetes mellitus relying on parental caregivers for disease management in China.

- Each interview performed in this study took 45$60 \mathrm{~min}$, with structure based on the theory of individual and family self-management, and formulated through expert evaluation of the research purpose, population and existent body of literature.

- To provide compelling evidence, heuristic content analysis was performed in order to summarise text data, and identify and refine emergent themes.

- This study is limited by the interpretation of the reviewers and coders.

- This is a single-centre study, with limited generalisability of the findings, thus a further multicentre study was needed.

parental caregiver and the child diagnosed with T1DM must learn how to manage the disease-associated tasks, with underlying financial, emotional and social impact on the family unit. ${ }^{1}$ With the incidence of T1DM increasing by $2 \%$ to $5 \%$ each year worldwide, ${ }^{2}$ an increasing number of families with young children are influenced by its burden. Although the incidence of T1DM in China is lower than that in Europe or the USA, being currently 5.6 per 100000 live births, ${ }^{3}$ China ranks fourth in the world for T1DM occurrence-and the number of cases is increasing each year. ${ }^{4}$ In addition, rural communities in China generally have fewer resources and the growing number of T1DM cases outside of urban centres would eventually increase the strain on Chinese parental caregivers. Thus, examining the situation of middle-income and low-income parents of children with T1DM in China is essential to improve T1DM care and long-term outcomes.

Management of T1DM in children involves changes in daily living activities that affect 
not only the child receiving care but also the caregiver. That includes continuous glucose monitoring (four or more times per day), ensuring insulin injections via insulin pump or injecting insulin multiple times a day, tracking and calculating daily carbohydrate intake as well as physical activity levels important to prevention of hypoglycaemic and hyperglycaemic episodes. ${ }^{56}$ Majority of children with T1DM under the age of 13 years are unable to self-manage their T1DM care, and instead rely heavily on their parental caregiver for disease management. ${ }^{7}$ Treatment for children with T1DM is aimed at ensuring stable blood glucose levels, minimising occurrence of potentially severe hypoglycaemic events and preventing long-term complications of diabetes as the child grows. ${ }^{8}$ These responsibilities presumably place immense psychological and financial stress on parental caregivers.

Owing to the relatively lower incidence of T1DM outside of urban centres in China, the emotional toll, financial burden and social isolation experienced by parental caregivers of young children with T1DM can be immense. Despite improvements in T1DM medications and treatment technologies, many children still experience adverse health effects due to invasive procedures or ineffective blood glucose control ${ }^{9}$; more than $58.6 \%$ of children with T1DM in China do not achieve sustained haemoglobin control (glycosylated haemoglobin lower than $7.5 \%),{ }^{10}$ which leads to complications that have adverse impact on the child's growth and long-term health, and place significant burden on caregivers and the family unit. This justifies a necessity to study T1DM care and its impact on parental caregivers through a social lens.

Previously, Rankin et $a l^{1}$ used qualitative methods to examine the strategies and motivations of children with T1DM and their caregivers, providing insights into how diabetes management can be improved. Other researchers have also demonstrated that successful disease management of children with T1DM not only requires the children to manage their individual health, but also requires their cooperation with caregivers who share the responsibility for the child's medical management. ${ }^{11}$ These burdens can, however, result in caregiving parents of children with T1DM feeling isolated and helpless when faced with the challenges of chronic disease management. Psychologically, caregivers may manifest a sense of self-doubt, guilt or anxiety, and many of them experience traumatic initial confusion as they try to integrate these new responsibilities into their family's routine when their child is first diagnosed. ${ }^{12}$ These feelings may be transient or persistent, and exacerbate if a child experiences hypoglycaemic events or other emergency situations that contribute to caregiver trauma and anxiety. ${ }^{13-15}$ Understanding the experiences of parental caregivers of children with T1DM could greatly improve clinical and social interventions, help parents adapt to the role of caregiver and achieve optimal health outcomes for children with T1DM. However, current research on the topic in China is primarily limited to quantitative studies on the quality of life (QoL), ${ }^{15}$ psychological state ${ }^{16}$ and coping style of the children or their parents. ${ }^{17}$

Qualitative research methodologies can provide actionable insights into the psychological state, behaviours, and motivations of patients and caregivers who manage T1DM. ${ }^{1}$ This study employs qualitative methods to examine the perceptions of parental caregivers of young children (aged 14 years or younger) with T1DM in China, their key challenges as caregivers during transition from full management of a young child with T1DM to an older child with increasing autonomy over his or her medical care. Thus, the present research is designed to provide actionable insights for improving social support and management of these patients, in a holistic context that considers the parental caregiver and family unit.

\section{METHODS}

\section{Patient and public involvement}

Patients or the public were not involved in the design, or conduct, or reporting, or dissemination plans of our research.

\section{Study population and design}

Qualitative research methods were employed to examine social, emotional, and experiential perceptions of parent(s) and/or legal guardian(s) of children diagnosed with T1DM, referred to as T1DM caregiving parents for the purpose of this article. Synchronous, in-person, semistructured interviews were conducted to collect qualitative data, and emergent heuristic content analysis was subsequently performed on transcripts. Eligible T1DM caregiving parents were identified from caregivers attending visits with children hospitalised or assessed in the Pediatric Neuroendocrinology Department of Shengjing Hospital, China Medical University in Shenyang from January 2018 to June 2019.

To be eligible for participation in the study interview, T1DM caregiving parents were required to (1) be the parent and/or legal guardian of a child 14 years of age or younger with diagnosed T1DM, and (2) be a primary caregiver during at least 6 months of continuous care for child being treated for T1DM during this period. ${ }^{18}$ T1DM caregiving parents were considered ineligible to participate in interviews if (1) the child with T1DM also experienced other significant comorbidities or chronic diseases; (2) the child with T1DM was considered to require immediate medical care or treatment and the study could pose an undue burden on the patient or caregiver; (3) T1DM caregiving parent was unable to communicate fluently in the local language of the investigator (Mandarin Chinese).

\section{Sampling methods and process}

Purposive non-probability sampling was used, in which eligible T1DM caregiving parents were approached for participation as they visited clinic. To ensure a representative sample, the heterogeneity of sample selection 
Table 1 Semistructured interview outline for parents of children aged $\leq 14$ years with type 1 diabetes mellitus

\begin{tabular}{|c|c|}
\hline Question \# & Description \\
\hline 1 & $\begin{array}{l}\text { Could you please talk about the situation when } \\
\text { your child was first diagnosed with type } 1 \\
\text { diabetes and your reaction at that time? }\end{array}$ \\
\hline 2 & $\begin{array}{l}\text { Could you please describe a day of caring for } \\
\text { a child with type } 1 \text { diabetes? }\end{array}$ \\
\hline 3 & $\begin{array}{l}\text { Since your child was diagnosed with diabetes, } \\
\text { what has been your biggest concern, or what } \\
\text { is the most difficult issue you have had to deal } \\
\text { with? }\end{array}$ \\
\hline 4 & $\begin{array}{l}\text { How do you help your child manage his/her } \\
\text { diet? }\end{array}$ \\
\hline 5 & $\begin{array}{l}\text { How do you help your child manage his/her } \\
\text { medication? }\end{array}$ \\
\hline 6 & $\begin{array}{l}\text { How do you help your child manage his/her } \\
\text { activities or exercise? }\end{array}$ \\
\hline 7 & $\begin{array}{l}\text { How do you help your child manage his/her } \\
\text { emotions? }\end{array}$ \\
\hline 8 & $\begin{array}{l}\text { How do you manage your own life while taking } \\
\text { care of your child? }\end{array}$ \\
\hline 9 & $\begin{array}{l}\text { As a caregiver, what are your needs in caring } \\
\text { for the child? }\end{array}$ \\
\hline 10 & $\begin{array}{l}\text { Do you think you are qualified for the role of } \\
\text { caring for a child with type } 1 \text { diabetes? }\end{array}$ \\
\hline
\end{tabular}

This outline has been translated from the original Mandarin Chinese version. All interviews were conducted in the local language of the investigator (Mandarin Chinese).

was expanded for T1DM caregiving parents' age, marital status, education level, and age and disease course of their children with T1DM. The study was discontinued when qualitative data reached saturation, which was expected to occur between 15 and 20 interviews, as previously described. ${ }^{19}{ }^{20}$ When the number of interviews reached 20 , the data in our research were saturated and no new information was obtained, so sampling was terminated.

\section{Data collection}

An Institutional Review Board-approved semistructured interview outline was used to ensure consistency while performing interviews. The interview structure was based on the theory of individual and family self-management, ${ }^{21}$ and formulated through expert evaluation of the research purpose, population and existent body of literature. The outline used in interviews is shown in table 1 . The planned duration of the interview was 45-60 min.

Upon arrival at the clinical site, the head nurse of the clinical unit familiar with the T1DM caregiving parent met the interviewee, led them to the interview site and made introduction. Prior to the start of the interview, the interviewer explained the purpose, significance, methods, rights of the interviewee and privacy protection measures. Written informed consent was then obtained before starting each interview.
The interview location was selected as an audiovisual classroom located in the Pediatric Neuroendocrinology Ward. This location was selected for the quiet environment, free of distractions. Interviews were conducted by the authors, who were provided with training on semistructured interviews and use of neutral, objective and non-leading language during the interview to maximise data integrity.

\section{Data transcription and coding}

Each interview was recorded using audio-recording devices, and digitally transcribed asynchronously (with 48 hours after each interview) by the researchers. Transcripts were recorded in MS Word (Microsoft, USA), and verified by a second researcher. To ensure data integrity, interviewees were provided with a copy of their interview transcript and allowed to suggest corrections, which, if appropriate, were assessed and integrated by the researchers upon review of the original recording.

Heuristic coding was performed using emergent grounded theory methods ${ }^{20}$ manually using transcripts imported into NVivo V.11.0 (QSR International, USA) using manual code to summarise text data, and identify and refine themes. Coding was verified by a second researcher; the numbers were used to identify the interviewees in place of their real names, DM1-DM20. Emergent themes and subthemes were identified.

\section{Data analysis and reporting}

Textual coding results in NVivo V.11.0 were reported as counts and percentages (data not shown), and themes/ subthemes were presented descriptively using qualitative analysis methods. All analyses were performed in the local language of the interviewer (Mandarin Chinese), and the data were analysed and collected simultaneously. The theme of the interviews was extracted using content analysis methodology by way of three-grade coding. Final results were translated to English, and all translations were performed by the researchers to ensure integrity of translations.

\section{RESULTS}

\section{Participant characteristics}

Saturation was reached when $20 \mathrm{~T} 1 \mathrm{DM}$ caregiving parents $(\mathrm{N}=20)$ completed interviews. Interviewed T1DM caregiving parents included 7 fathers and 13 mothers (gender roles were self-identified by the interviewee), aged 30-53

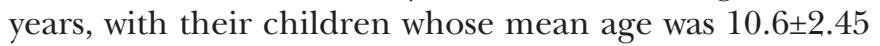
years. Of these patients, 8 were caregivers of children with T1DM that were treated with insulin pumps, and 12 were caregivers of children with T1DM that were treated with subcutaneous injections. Sociodemographic information for T1DM caregiving parents completing interviews and demographic and clinical condition of their children are summarised in table 2.

By analysing the transcripts of interviews, five major emergent themes were observed consistently throughout 
Table 2 Characteristics of parental caregivers of children with T1DM interviewed

\begin{tabular}{|c|c|}
\hline Characteristic & $\begin{array}{l}\text { Interviewee } \\
(n=20)\end{array}$ \\
\hline \multicolumn{2}{|l|}{ Children } \\
\hline Age (years), mean \pm SD & $10.6 \pm 2.45$ \\
\hline Onset age of T1DM, mean \pm SD & $7.2 \pm 2.4$ \\
\hline \multicolumn{2}{|l|}{ Insulin regimen, n (\%) } \\
\hline Insulin pump use & $8(40)$ \\
\hline Daily injections & $12(60)$ \\
\hline \multicolumn{2}{|l|}{ Gender, n (\%) } \\
\hline Male & $7(35)$ \\
\hline Female & $13(65)$ \\
\hline
\end{tabular}

\section{Parents}

Age (years), mean \pm SD

$39.45 \pm 6.21$

Gender, n (\%)

Male (self-identified as father) 8 (40)

Female (self-identified as mother)

$12(60)$

Current employment status, $\mathrm{n}(\%)$

$\begin{array}{ll}\text { Full-time } & 8(40) \\ \text { Part-time } & 6(30) \\ \text { Not working } & 6(30) \\ \text { Highest education level, n (\%) } & \\ \begin{array}{l}\text { Junior high (middle) school or some high } \\ \text { school }\end{array} & 6(30) \\ \begin{array}{l}\text { High school diploma } \\ \begin{array}{l}\text { Technical school (2-year degree or } \\ \text { equivalent) }\end{array}\end{array} \\ \begin{array}{l}\text { Bachelor’s degree (4-year degree or } \\ \text { equivalent) }\end{array} & 3(30) \\ \begin{array}{l}\text { Monthly income (¥/US\$), n (\%) } \\ <3077 / 500\end{array} & 5(25) \\ 3077-11428 / 500-1700 & 5(25) \\ >11428 / 1700 & 9(45)\end{array}$

T1DM, type 1 diabetes mellitus.

the interview data: (1) persistent psychological stress; (2) family function changes; (3) challenges in daily management; (4) excessive economic burden; (5) lack of support system. All 13 minor subthemes within these 5 themes are summarised in table 3 . The themes/subthemes are further characterised below.

\section{Theme of persistent psychological stress}

Persistent psychological stress was identified as a prominent theme across interviews, with four key subthemes emerging from coding:

\section{Catastrophic emotional experience}

In acute period following diagnosis, parents often experienced emotions that can be described as catastrophic,
Table 3 Themes and subthemes emerging from interviews of parental caregivers of children with T1DM

\begin{tabular}{|c|c|}
\hline Themes & Subthemes \\
\hline $\begin{array}{l}\text { Persistent } \\
\text { psychological } \\
\text { stress }\end{array}$ & $\begin{array}{l}\text { 1. Catastrophic emotional experience } \\
\text { 2. Emotional distress based on negative } \\
\text { emotions } \\
\text { 3. Altered sense of self-efficacy } \\
\text { 4. Perceived increased responsibility for } \\
\text { parenting }\end{array}$ \\
\hline $\begin{array}{l}\text { Family function } \\
\text { changes }\end{array}$ & $\begin{array}{l}\text { 1. Changes in patterns of family life } \\
\text { 2. Changes in parental roles and functions }\end{array}$ \\
\hline $\begin{array}{l}\text { Challenges } \\
\text { in daily } \\
\text { management }\end{array}$ & $\begin{array}{l}\text { 1. Technical difficulties managing blood } \\
\text { glucose } \\
\text { 2. Difficulties in emotional regulation and } \\
\text { managing parent-child conflict } \\
\text { 3. Transition from parental management to } \\
\text { self-management as the child ages }\end{array}$ \\
\hline $\begin{array}{l}\text { Excessive } \\
\text { financial burden }\end{array}$ & $\begin{array}{l}\text { 1. Burden of disease treatment } \\
\text { 2. Changes in economic sources }\end{array}$ \\
\hline $\begin{array}{l}\text { Lack of social } \\
\text { support system }\end{array}$ & $\begin{array}{l}\text { 1. Limited social activities } \\
\text { 2. Insufficient other support systems }\end{array}$ \\
\hline
\end{tabular}

T1DM, type 1 diabetes mellitus.

including shock, fearfulness, frustration, hopelessness, sadness and feelings that disaster is imminent.

When the doctor told me that my child was diabetic, I felt like [I was] struck by lightning and the sky was falling. My child's life is basically over. (DM2)

\section{Emotional distress based on negative emotions}

Negative emotions observed in T1DM caregiving parents primarily included continual worry, anxiety, sadness, stigma, annoyance and guilt. Worry was embodied in anxiety and sadness, often with connections to the uncertainty of disease progression in their child. Some parents also experienced symptoms of worry and invasive thoughts about the potential for their children to be discriminated in the future because of their illness, leading some to even report hiding their child's illness in common social contexts. Further, parents reported feeling guilty linked to social isolation and dietary restrictions experienced by their child, aetiology of illness (often linked to limited clinical understanding of T1DM) or feeling of being 'at fault' for their child's condition.

It's still like a sword hanging over my head. I don't know when the complications will come. I live with fear every day. (DM2)

I don't want people around to know that my child has diabetes. Diabetes is an undead cancer. Thinking about it in another way, who wants his child to marry a diabetic in the future? You may only have to marry someone who also has diabetes. My child doesn't want her classmates to know that she is different from others. (DM6) 
My thoughts are that he is too young and suffers too much. He has to get injections and blood tests every day, and his fingers are pierced constantly. As a parent, I feel like a failure. I have not taken good care of my child and have been busy with work. I feel like I neglect taking care of him. (DM5)

\section{Altered sense of self-efficacy}

T1DM caregiving parents also showed self-doubt owing to lack of experience in chronic disease care. In the most extreme cases, these feelings manifest as a severe lack of self-compassion, where parents expressed doubt in their ability to competently care for their child.

Taking care of [my daughter], it's not that I think I can or can't, but that I must be able to do. It's like a parent's obligation. If I can't, what else can she do? It's not something I can or can't do. It's something I must be able to do. (DM6)

\section{Perceived increased responsibility for parenting}

T1DM caregiving parents reported perceiving a heavier burden of responsibility to manage their child's disease and remain hypervigilant, in particular for young children with T1DM not capable of self-managing. Parents perceive that, compared with children without T1DM, both parents and children bore additional responsibilities.

Now our child is too young to take care of herself. As parents, we are duty-bound, we have to be good supervisors. We supervise our child's diet, exercise, blood glucose testing and injections. Although we are not professionals, we will be dedicated to protecting our child's health. (DM19)

\section{Family function changes}

Changes in family life included two prominent subthemes.

\section{Changes in patterns of family life}

Changes in routine patterns of daily living within the family unit were consistently reported by T1DM caregiving parents. These changes included changes in family activities designed to assist children in adapting to their life after T1DM diagnosis. On one hand, parents reported striving to retain normalcy for their children; however, the child's T1DM was also often reported to be disruptive to others, particularly other children, in the family unit. Parents also reported aiming to incorporate blood glucose measurement in routine daily living activities of the family unit, with mixed success.

It is inevitable that [when living with a child with T1DM] you can't be the same as other families. We have to consider our child's physical strength and whether [he] can eat regularly. Especially when faced with a table full of good food, it is uncomfortable for the child to see others eating. (DM19)
Now we guide our child to think that measuring blood glucose and injecting insulin is a routine in life, just like showers before bed. We don't want our child to feel that injecting insulin before meals is a burden. (DM11)

\section{Changes in parental role and function}

T1DM caregiving parents consistently reported that they perceived differences between their 'normal' role and function compared with their prior lifestyle before their child's diagnosis. Specifically, T1DM caregiving parents expressed that their child's diagnosis affected their future career planning, life focus and goals, and often resulting in a greater amount of time spent tending medical needs of their child.

Now I rarely focus my energy on the company [I work for], just get off work as soon as possible. I used to leave early and return late to make money. Now I quit my job and found a new one that can make a living while taking care of my child. When she is on vacation, so am I. (DM5)

In some cases, significant housing and job/school changes are made to accommodate the child's T1DM care.

My family is in the countryside, but our child comes to a school in the city. Since our child has the disease, diabetes, and cannot live in school, I have to accompany him to study. My child and I rented a house near the school, which is convenient for me to take care of him, and we will return to the countryside during vacation, where his father works. (DM14)

\section{Challenges in daily management theme}

Challenges in daily management were consistently reported by T1DM caregiving parents, including three subthemes:

\section{Technical difficulties in blood glucose management}

T1DM caregiving parents reported technical difficulties in blood glucose management, including unsatisfactory or irregular blood glucose levels, primarily associated with dietary control, exercise compliance, untimely blood glucose monitoring and insulin injection dosage adjustment. Parents expressed that lack of self-management, often owing to social and educational obligations, was often a key concern.

$\mathrm{He}$ is in the second grade of junior high school. There is a lot of tutoring outside school. He has to get up at 5:30 in the morning to study and finish school at 5:30 in the evening. If goes to the tutoring class, he returns at 8:30. There is no time to exercise. At school, his blood glucose control was poor [but] it is impossible to ask him to leave school to take measurements before and after meals. (DM15) 
Emotional regulation and managing parent-child conflict

In addition to the regulation of T1DM caregiving parents' own emotions, interviewees also reported difficulty in assessing and managing their child's emotional and psychological needs.

[My daughter with T1DM] feels that if her classmates know she is sick and can't be cured, she will be inferior to others. Often it was lunch at noon, and she went to the toilet to get an injection, because she is afraid of being discriminated against by her classmates or something. Our child's self-esteem is strong, so she ran to the toilet for injections; at that time, if another child went to the toilet, she would be frightened, remove the needle and hurriedly put it away. She would not press and was still bleeding. As a parent, I feel distressed, but I don't know how to help the child to feel better. (DM14)

Interviewees consistently reported that parent-child conflict stemmed from inability to communicate effectively and perception of their children's poor compliance with disease management. As children age and their sense of autonomy increases, parents reported difficulty in transitioning to stages where their child exerts greater autonomy over their T1DM care and monitoring. In particular, interviewees reported resistance from their child, and perceptions that the child felt controlled by the parent's actions.

I understand that the child is also upset and there is no place to vent. I restrict her diet and control her blood glucose measurements. How can she not resist psychologically? I feel that I can't get into her heart, I don't know how to get along with her. (DM20)

Transition from parental management to self-management as the child ages

With changes in their child's growth and developmental stage, the roles and function of children and parents in T1DM management shift. However, premature transfer of diabetes management tasks to children with T1DM is now considered a factor leading to poor blood glucose control. Many T1DM caregiving parents expressed uncertainty or frustration on transition timing.

In the first year, we helped her with her insulin injections, and then she did it by herself for the next two years. The blood glucose monitoring at night was not done, so the glucose control was not good. Such an old child is really difficult to manage, half-sensible but not sensible. (DM15)

\section{Excessive financial burden theme}

T1DM caregiving parents consistently reported the excessive financial burden of caring for a child with T1DM, including high cost of treatment. This burden was often cited as a factor for job and educational changes, affecting family members' circumstances. Due to the long-term nature of treatment, medications and injection supplies are consumable items with sustained cost impact. Furthermore, caring for a young child with T1DM often requires care around the clock, with some parents reporting that one of the parents gave up employment, changed employment or reduced hours to provide adequate care for their child, often decreasing household income and adding further financial stress to middle-income and lowincome families.

Using an insulin pump is a great economic pressure. It costs nearly 20,000 CNY [about $3000 \mathrm{USD}$ ] a year. One tube is normally more than $110 \mathrm{CNY}$ [about 17 USD]. I will buy some during sales and let my friends buy some more from other channels. A tube can be used for three days. It costs nearly 20,000 CNY [about 3000 USD] a year. (DM2)

\section{Lack of social support systems theme}

The lack of support system primarily includes limited social activities and insufficient social support system, as described below:

\section{Limited social activities}

At present, the family structure in China is dominated by a typical nuclear family, and children are generally a primary focus of the family unit. Once a child is diagnosed with T1DM, T1DM caregiving parents reported feeling disruption in the social activities of the family unit. In particular, mothers in the interview often left their employment, changed careers or reduced hours to be able to care for their child with T1DM, thus narrowing their social circle to the immediate family members. This transition can result in social isolation and limit normal social activities of the parent.

Since my child had a ketosis coma, I have never dared to relax again. I have lost myself. Every day in the year, there are no more visits to relatives or friends. (DM10)

\section{Insufficient other support systems}

Insufficient systems of social support were a common concern of T1DM caregiving parents, especially those with children reaching school age and assuming autonomy over their care during school hours.

Unlike other countries, our children do not have diabetes nurses in school. When the child is at school, every time the teacher calls, I am terrified, always scared that something bad will happen. If the child's blood glucose is low, does the teacher know how to handle it? Will it be delayed? (DM12)

\section{DISCUSSION}

This study aimed to qualitatively examine perception of common challenges among parental caregivers of 
children with T1DM. Using grounded theory, a method based on social science research, ${ }^{20}{ }^{21}$ researchers examined and consolidated emergent themes from interview transcripts. In this study, parental caregivers of children with T1DM consistently reported persistent psychological stress, changes in routine functions of the family unit, challenges in daily disease management for both the child and parental caregiver, financial strain and disruption of social activities. Thus, this qualitative study and the following sections aim to provide actionable insights for both future research and patient support programmes.

\section{Reducing persistent psychological strain in parental caregivers of children with T1DM}

This study showed that parental caregivers of children with T1DM were particularly susceptible to psychological stress during the early stages after their child's first T1DM diagnosis. These stressors manifested as recollections of negative emotions leading to emotional distress, including shock, sadness and anxiety. Further, repeat insulin injections and finger blood glucose monitoring in children posed not only technical challenges for non-medical professional caregivers, but also emotional distress in parental caregivers. Shortly after a child's diagnosis, many parental caregivers reported feelings of disbelief, resulting in catastrophic emotional disturbances linked to shock, fear, frustration, despair and sadness. These findings are consistent with other quantitative psychological studies demonstrating post-traumatic stress disorder (PTSD) symptoms in caregivers ${ }^{2022-24}$; however, the use of qualitative interview methods enables additional insights into the character of reflective perceptions of parental caregivers, and how such condition can be relieved. Our study suggests that the emotional effects of 'invisibility' of the T1DM prior to diagnosis can trigger guilt and anxiety that exacerbate psychological stressors. Further, young age of the child and uncertainty of social impact can also increase psychological pressure on the caregiver, leading to anxiety and PTSD manifestations. In some cases, these stressors can lead to catastrophic emotional experiences occurring in the early stage of diagnosis and during a child's hospitalisation, which is consistent with other research. ${ }^{25}$

In particular, following the hospital discharge of a child with T1DM, parental caregivers in this study noted a variety of negative emotions, in particular poorly controlled worry, anxiety, sadness, stigma, annoyance and guilt. During the course of our interviews, it was found that worry, anxiety and sorrow were closely linked to uncertainty of disease progression. This observation is consistent with prior studies that have shown parental caregivers of children with T1DM experience a heightened level of disease uncertainty compared with caregivers of other chronic states, which can exert adverse effects on the health and psychological condition of the parental caregivers and the children they care for. ${ }^{26}$ Thus, medical staff should pay particular attention to these potential effects in early stages of the disease progression.
Parental caregivers, in part due to their emotional bond with their child, are also affected emotionally by perceived stigma. Stigma refers to a kind of inner shame caused by illness that is viewed as a deficiency, which negatively affects patient psychology and can contribute to non-compliance or delay of critical treatment and monitoring of T1DM. ${ }^{27}$ During the interviews conducted in this study, some parents of children with T1DM expressed that diabetes would affect their child's future employment, marriage and social standing, in some cases going so far as to hide their child's condition to avoid perceived discrimination. Stigma affects caregivers by playing on their guilt, which may be exacerbated by 'causing' pain to the child through blood tests and limiting activities or diet. Some parents also have limited scientific understanding of the illness, and perceive the disease to be a result of neglect in care that can further exacerbate feelings of guilt, anxiety and depression. Parents' persistent emotional distress affects their own physical and mental health, thereby affecting management of blood glucose control in their children. ${ }^{28}$ Thus, whether or not parental caregivers have let the stigma to influence their emotional state concerns medical staff, related to the treatment of children with T1DM.

As prior research has shown, the self-efficacy of parental caregivers in diabetes management is related to the effectiveness of blood glucose control. ${ }^{29}$ In the interviews conducted during this study, parental caregivers emphasised expectations placed on the mother's role, and their increased sense of self-efficacy. Parents that perceived themselves as competent in the role of caregiver consistently experienced less emotional distress. Through analysing interviews, this study found that the psychological burden of parents primarily derives from the following courses: (1) pressure of blood glucose management in children, especially in diet management; (2) children's physical and mental pain caused by insulin injections, blood glucose monitoring and diet restrictions; (3) mood changes in children due to illness and (4) the impact of the disease on the children's future. These insights can be used to design integrated patient management programmes that consider both parental caregivers' emotional health and the medical condition of the child with T1DM.

\section{Supporting the transition of parents into an evolving caregiver role}

Becoming a caregiver of a child with T1DM is disruptive not only to the parent(s), but also to the family unit. Furthermore, the emotional burden on parental caregivers is increased by an evolving need for autonomy over T1DM care as children age. For younger children with T1DM, parental caregivers will need to dedicate substantial time and financial resources to their child's daily care, such as regular blood glucose measurement, injecting insulin, monitoring their diet and physical activities, and handling emergent issues. Common challenges in daily management include difficulty in blood glucose 
management, emotional management, parent-child conflict and the transition from parental management to self-management. While technology has improved T1DM care through the use of insulin pumps and continuous blood glucose monitoring, often young children may not have access to these technologies or compliance may not be possible. ${ }^{30}$ These changes in activities of daily living in the family unit also impact relationship between parents and children, leading to conflict. Thus, additional care is needed in the community and clinical setting to support parents transitioning through the various stages of T1DM caregiver roles.

Parental caregivers of children with T1DM also face challenges in transitioning their role to manage their child's increased autonomy with age. In this study, it was apparent from interviews that, even at a young age, issues of the child's autonomy could affect the parent-child relationship and lead to family conflict. Previous studies have shown that families often experience conflicts in chronic disease care setting. In particular, children with T1DM and high levels of family conflict have been shown to have poorer blood glucose control and lower overall QoL. ${ }^{31}{ }^{32}$ As young children grow into adolescence, these conflicts may become more common or escalate. Khandan et $a l^{33}$ found that when children with T1DM reached the age of 8-11 years, their parents begin to transfer diabetes management responsibility to them, gradually transitioning from 'parental responsibility' to 'cooperative support'. While parents have a high degree of control over their young child's medical care, they may require outside support from clinicians or the community in transitioning these responsibilities as their child enters adolescence. Appropriate mental health and community support may thus improve outcomes among these children and their caregivers and help to achieve an effective transition to self-management as these children enter adolescence.

\section{Improving financial and social support systems for parental caregivers of children with T1DM in China}

In this study, parental caregivers of children with T1DM consistently reported a strain on household finances related to their child's care and disposable supplies, and a lack of social support. In the majority of cases, discussed in the present study, expenses were covered by insurance only during hospital stay, but after discharge the expenses were paid by parents/guardians. Insulin medication was also partly covered by health insurance, but the reimbursement rate varied depending on the type of health insurance (up to $90 \%$ ). Similar to the results of other studies, ${ }^{34}$ medications and disposable devices used for long-term treatment place a substantial and ongoing burden on these families, often affecting housing, employment and economic opportunities for middleincome and low-income families. Financial burden not only affects the physical and mental health of parental caregivers, but also limits or delays selection of treatment options that can influence the long-term prognosis of children with T1DM.

Furthermore, the lack of social support and relative social isolation of caregivers, particularly those that reduced hours or left jobs to act as primary caregivers (most common among mothers), was consistently reported in this study. The lack of support systems was apparent from limited family social activities, which often negatively impacted the parental caregiver's emotional state. Compared with other developed regions, China currently has a lack of diabetes nurses in kindergartens and primary or secondary schools. Thus, preschool and school-aged children have to assume the responsibility of diabetes self-management during school hours. In addition, many parents in this study reported that blood sugar control was not ideal during school hours, because of selfesteem issues or poor self-control. Therefore, we propose that we should, as a healthcare system, selectively learn from the successful experience of other countries ${ }^{35}$ and gradually implement training for school personnel and other personnel who contact with children with diabetes, to improve the social support system for children with diabetes.

Notably, this research is limited by the interpretation of the reviewers and coders. In particular, all interviewees and researchers were from a single hospital, which limits the generalisability of the findings to a broader population. However, these insights provide greater depth than mere quantitative characterisations, and may aid in improving both psychological and physical outcomes of children with T1DM and their parental caregivers.

\section{CONCLUSIONS}

This qualitative study examine the emergent themes through a series of interviews that address the perceptions of parental caregivers of children with T1DM, giving voice to the common challenges faced by parental caregivers as their young children are first diagnosed with T1DM and slowly gain autonomy for their own chronic disease management as they age. This research demonstrates common themes of persistent psychological stress, difficulty managing changes in family function, challenges in daily disease management, challenges of excessive financial burden and the impact of a lack of social support for parental caregivers. By characterising these common perceptions and experiences, we can better prepare healthcare providers to support both the child with T1DM and parental caregivers as they adapt to medical management of T1DM at different stages, thereby improving their self-management capabilities.

Acknowledgements The authors wish to thank all the parents who share their experiences and insights in this study. They made this study achievable.

Contributors The study was supervised by LF. The study was performed by HT. Data were coded and interpreted by FQ and HT. The manuscript was written by HT and LF. LF is responsible for the overall content.

Funding The authors have not declared a specific grant for this research from any funding agency in the public, commercial or not-for-profit sectors. 
Competing interests None declared.

Patient and public involvement Patients and/or the public were not involved in the design, or conduct, or reporting, or dissemination plans of this research.

\section{Patient consent for publication Not required.}

Ethics approval This study involves human participants and was conducted in accordance with the Declaration of Helsinki and was approved by the Institutional Review Board (IRB) of Shengjing Hospital, China Medical University, Shenyang, China (approval no. 2018PS362K). Participants gave written informed consent prior to participating in interviews.

Provenance and peer review Not commissioned; externally peer reviewed. Data availability statement Data are available upon reasonable request.

Open access This is an open access article distributed in accordance with the Creative Commons Attribution Non Commercial (CC BY-NC 4.0) license, which permits others to distribute, remix, adapt, build upon this work non-commercially, and license their derivative works on different terms, provided the original work is properly cited, appropriate credit is given, any changes made indicated, and the use is non-commercial. See: http://creativecommons.org/licenses/by-nc/4.0/.

\section{ORCID iD}

Ling Fan http://orcid.org/0000-0001-5276-3921

\section{REFERENCES}

1 Rankin D, Harden J, Barnard K, et al. Barriers and facilitators to taking on diabetes self-management tasks in pre-adolescent children with type 1 diabetes: a qualitative study. BMC Endocr Disord 2018;18:71.

2 Craig ME, Hattersley A, Donaghue KC. Definition, epidemiology and classification of diabetes in children and adolescents. Pediatr Diabetes 2009;10:3-12.

3 Patterson C, Guariguata L, Dahlquist G, et al. Diabetes in the young - a global view and worldwide estimates of numbers of children with type 1 diabetes. Diabetes Res Clin Pract 2014;103:161-75.

4 Cho NH, Shaw JE, Karuranga S, et al. IDF diabetes atlas: global estimates of diabetes prevalence for 2017 and projections for 2045. Diabetes Res Clin Pract 2018;138:271-81.

5 Haas L, Maryniuk M, Beck J, et al. National standards for diabetes self-management education and support. Diabetes Care 2014;37:S144-53.

6 Urakami T. Severe hypoglycemia: is it still a threat for children and adolescents with type 1 diabetes? Front Endocrinol 2020;11:609.

7 Erickson K, Freeborn D, Roper SO, et al. Parent experiences raising young people with type 1 diabetes and celiac disease. J Pediatr Nurs 2015;30:353-63

8 Rewers MJ, Pillay K, De Beaufort C. Assessment and monitoring of glycemic control in children and adolescents withdiabetes. Pediatric Diabetes 2014;15:102-14.

9 Ying GMW, Wei G. Self-monitoring of blood glucose level in children with type 1 diabetes and its influencing factors. J Nurs Sci 2010;25:6-7.

10 Ling P, Zhang Y, Luo SH, et al. [Glycemic control and its associated factors in children and adolescents with type 1 diabetes mellitus] Zhonghua Yi Xue Za Zhi 2018;98:3762-6.

11 Harrington KR, Boyle CT, Miller KM, et al. Management and family burdens endorsed by parents of youth $<7$ years old with type 1 diabetes. J Diabetes Sci Technol 2017;11:980-7.

12 Lawton J, Waugh N, Barnard KD, et al. Challenges of optimizing glycaemic control in children with type 1 diabetes: a qualitative study of parents' experiences and views. Diabet Med 2015;32:1063-70.

13 Buckloh LM, Wysocki T, Antal H, et al. Learning about long-term complications of pediatric type 1 diabetes: parents' preferences. Child Health Care 2016;45:399-413.
14 Patton SR. Hypoglycaemic-related fear in parents of children with poor glycaemic control of their type 1 diabetes is associated with poorer glycaemic control in their child and parental emotional distress. Evid Based Nurs 2011;14:5-6.

15 Wei H, LV J, Heying A. Quality of life and influencing factors of parents of children and adolescents with type 1 diabetes. Guangdong Med J 2016;37:2324-6.

$16 \mathrm{Li} \mathrm{J}$, Xiurong C. Research progress on factors affecting the fear of hypoglycemia in parents of type 1 diabetic children/adolescents. J Nurs Sci 2019;26:31-5.

17 Rui W, Zhang L, Li F. Investigation on the coping style of parents of adolescents with type 1 diabetes. Chinese Nurs Res 2016;30:2469-72.

18 Adler ABP, Colagiuri S. Classification of diabetes mellitus. World Health Organization, 2019. Available: https://apps.who.int/iris/rest/ bitstreams/1233344/retrieve

19 Saunders B, Sim J, Kingstone T, et al. Saturation in qualitative research: exploring its conceptualization and operationalization. Qual Quant 2018;52:1893-907.

20 Glaser BG, Strauss AL. The discovery of grounded theory: strategies for qualitative research. Social Forces 1967;46.

21 Charmaz K, Belgrave L. The Blackwell encyclopedia of sociology. Grounded Theory 2015

22 Landolt MA, Ribi K, Laimbacher J, et al. Posttraumatic stress disorder in parents of children with newly diagnosed type 1 diabetes. $J$ Pediatr Psychol 2002;27:647-52.

23 Landolt MA, Vollrath M, Laimbacher J, et al. Prospective study of posttraumatic stress disorder in parents of children with newly diagnosed type 1 diabetes. J Am Acad Child Adolesc Psychiatry 2005;44:682-9.

24 Bowes S, Lowes L, Warner J, et al. Chronic sorrow in parents of children with type 1 diabetes. J Adv Nurs 2009;65:992-1000.

25 Iversen AS, Graue M, Haugstvedt A, et al. Being mothers and fathers of a child with type 1 diabetes aged 1 to 7 years: a phenomenological study of parents' experiences. Int J Qual Stud Health Well-being 2018;13:1487758.

26 Amiri F, Vafa M, Gonder-Frederick L, et al. Evaluating fear of hypoglycemia, pediatric parenting stress, and self-efficacy among parents of children with type 1 diabetes and their correlation with glycemic control. Med J Islam Repub Iran 2018;32:119.

27 Capistrant BD, Friedemann-Sánchez G, Pendsey S. Diabetes stigma parent depressive symptoms and type-1 diabetes glycemic control in India. Soc Work Health Care 2019;58:919-35.

28 Perez L, Romo LK, Bell T. Communicatively exploring uncertainty management of parents of children with type 1 diabetes. Health Commun 2019;34:949-57.

29 Noser AE, Patton SR, Van Allen J, et al. Evaluating parents' selfefficacy for diabetes management in pediatric type 1 diabetes. $J$ Pediatr Psychol 2017;42:296-303.

30 Haslund-Thomsen H, Hasselbalch LA, Laugesen B. Parental experiences of continuous glucose monitoring in Danish children with type 1 diabetes mellitus. J Pediatr Nurs 2020;53:e149-55.

31 Luyckx K, Seiffge-Krenke I, Missotten L, et al. Parent-adolescent conflict, treatment adherence and glycemic control in type 1 diabetes: the importance of adolescent externalising symptoms. Psychol Health 2013;28:1082-97.

32 Spencer JE, Cooper HC, Milton B. The lived experiences of young people (13-16 years) with Type 1 diabetes mellitus and their parents-a qualitative phenomenological study. Diabet Med 2013;30:e17-24

33 Khandan M, Abazari F, Tirgari B, et al. Lived experiences of mothers with diabetic children from the transfer of caring role. Int $J$ Community Based Nurs Midwifery 2018;6:76-88.

34 Rankin D, Harden J, Waugh N, et al. Parents' information and support needs when their child is diagnosed with type 1 diabetes: a qualitative study. Health Expect 2016;19:580-91.

35 Edwards D, Noyes J, Lowes L, et al. An ongoing struggle: a mixedmethod systematic review of interventions, barriers and facilitators to achieving optimal self-care by children and young people with type 1 diabetes in educational settings. BMC Pediatr 2014;14:228. 